\title{
Business process management and supply chain collaboration: a critical comparison
}

\author{
Jiraporn Pradabwong ${ }^{1}$. Christos Braziotis ${ }^{1} \cdot$ Kulwant S. Pawar $^{1} \cdot$ \\ James Tannock ${ }^{2}$
}

Received: 2 April 2015/Accepted: 14 July 2015/Published online: 13 October 2015

(C) The Author(s) 2015. This article is published with open access at Springerlink.com

\begin{abstract}
The link between a firm and supply chain (SC) members has been recognised as one of the key issues for ensuring business success and achieving competitive advantage. Indeed, working across organisational boundaries is required to accomplish effective responses to customers' needs. Our preliminary research confirmed that there are positive relationships between business process management (BPM), supply chain collaboration (SCC), collaborative advantage and organisational performance. This study is a step further and uses a multiple case design to illuminate the results and gain a greater understanding from extensive discussions about these relationships. By means of semi-structured interviews, the three main issues were identified as: (1) the link between BPM and organisational performance; (2) the link between BPM and SCC; and (3) the contextual factors and benefits achieved from working collaboratively with SC partners. The different scenarios of the link between BPM and SCC were developed in a taxonomy, and the case studies were used to
\end{abstract}

Jiraporn Pradabwong

lixjp8@nottingham.ac.uk

Christos Braziotis

Christos.Braziotis@nottingham.ac.uk

Kulwant S. Pawar

Kulwant.Pawar@nottingham.ac.uk

James Tannock

j.tannock@hull.ac.uk

1 Division of Operations Management and Information Systems, Centre for Concurrent Enterprise, Nottingham University Business School, Wollaton Road, Nottingham NG8 1BB, UK

2 Logistics Institute, Hull University Business School, Hull HU6 7RX, UK illustrate the experience of intra- and inter-organisational practices in the developing economy of Thailand. The case studies' results explain in depth that both BPM and SCC are important for improving organisational performance and competitiveness. BPM not only improves organisational performance directly, but also assists with collaborative activities that in turn help to improve internal capabilities. Additionally, the comparisons in issues relating to firm size, industry type, relationship closeness and relationship length were also included in this study.

Keywords Business process management - Supply chain collaboration $\cdot$ Collaborative advantage $\cdot$ Case study

\section{Introduction}

Early definitions of supply chain management (SCM) typically emphasised the management of activities and material flows, whereas more recent SCM definitions have largely focused on managing the supply chain (SC) as one system with clear strategic goals [1]. Hence, there has been a shift towards managing SC members to gain mutual benefits and a concentration on a SC-centric rather than an organisation-centric view. Within a SC, firms need to provide basic management resources, both internally and in relation to their SC partners, to develop main capabilities in relation to SCM execution [2]. Hence, there has been a change of focus from the process function to $\mathrm{SC}$, which has been characterised by specific attention to partnerships, relationships, networks, value creation and value constellations [3]. Collaboration is known as a "silver bullet" in many areas of SCM [4, p. 314], which illustrates the importance many firms place on it. Building relationships between companies rather than working 
individually can lead to competitive advantage, resulting in organisational performance improvement [5]. Regarding the importance of intra- and inter-organisational relationships, various researchers have recognised that the link between a firm and its SC members is one of the key issues to ensure business success and competitive advantage $[6,7]$. Companies that have developed their internal business process with their suppliers and customers are in a better position to produce and distribute their products at a lower cost and satisfy service level requirements [8]. Hence, firms and their SC members working collaboratively by opening communication and sharing resources, risks and rewards should enjoy mutual benefits. For instance, Hsu et al. [6] studied the impact of SCM practices on operations capability and firm performance. The study illustrated the idea that SCM practices mediate the impact of operations capability on organisational performance. Flynn et al. [9] indicated that SC integration (supplier, internal and customer integration) is beneficial to firm performance. Previous studies have also provided an illustration of the relationships between specific paradigms of internal practices [such as lean manufacturing and enterprise resource planning (ERP) systems] and the SC $[10,11]$. However, there is a need for a comprehensive study of other aspects that link SC partners in their attempts to achieve competitive advantage and improve organisational performance.

Regarding business process management (BPM) and supply chain collaboration (SCC), prior research has suggested that both BPM and SCC are important for improving performance and competitiveness [11-14]. For instance, Min et al. [13] developed a model of SCC to demonstrate the relationships between the antecedents of collaboration, collaboration itself and its consequences. The antecedents included strategic intent, internal alignment, relationship orientation, relationship-specific investment, a free flow of information and heightened communication and formalisation. Collaboration was shown to have a moderating effect between the antecedents and the consequences (efficiency, effectiveness and profitability). Simatupang and Sridharan [14] highlighted that a firm that focuses on BPM practices should be able to support collaborative activities with its SC partners. There is a positive relationship between internal SCM resources and joint SCM resources, which in turn affect collaborative SCM processes and SCM execution [12]. However, the previous literature lacks empirical testing of the relationship between BPM and SCC, which are important for leveraged performance. The link between these two aspects needs to be identified to provide a better understanding of how intra-organisational development regarding BPM practice can help with collaborative activities and of the benefits that can, thereby, be achieved.
The early stage of our research empirically tested the interrelationships between BPM, SCC, collaborative advantage and organisational performance [15]. It provides empirical evidence that there is a positive relationship between the relationships under investigation. Hence, it only indicated the results in terms of the significance or non-significance of each hypothesis [15]. However, prior research still lacks insights into the actual practices of BPM and SCC, especially in the manufacturing sector in a developing economy. Based on this research gap, we argue that there is a need to capture instances of practitioners' views of the relationships between BPM, SCC, collaborative advantage and organisational performance, and to develop an understanding of the underlying factors guiding these interrelationships. Therefore, this research aims to provide a detailed understanding of the meanings, actions and opinions of real-world practitioners in their specific contextual situations and their experiences of the use of BPM practices, collaboration with SC partners and benefits achieved in terms of collaborative advantage and organisational performance. More specifically, this research focuses on the manufacturing sector in a developing economy, namely Thailand, an aspect which has mainly been neglected. The main research question that guided our research can be identified as: "How do BPM and SCC interrelate to drive collaborative advantage and organisational performance?". This can be broken down into three research sub-questions: (1) "How does BPM help to improve organisational performance?"; (2) "How does BPM help in collaborative activities?"; and (3) "How do contextual factors impact on the link between BPM and SCC and the relationship benefits?".

To answer these questions, a multi-case approach was adopted using four medium and large companies from the electronics and automotive industries in Thailand. Based on earlier research, BPM represents intra-organisational development, and we ascertained four elements of BPM, namely strategic alignment, information technology (IT), process orientation and improvement and people involvement [15]. We identified four elements of SCC, namely information sharing and communication, sharing common goals, joint activities and incentive alignment. These important elements of BPM and SCC were selected based on the most commonly used ones in previous research (based on the number of citations from Harzing's "Publish or Perish" (23 July 2014). The benefits were indicated in terms of collaborative advantage and organisational performance, and a framework was developed to explain these relationships. Next, a taxonomy was developed to identify different types of internal development (BPM) and external developments (SCC) and to illustrate how companies' performance can be improved. The taxonomy can help SC managers to enhance their understanding of intra- and 
inter-organisational development and shape the ways to manage and improve their SC to achieve higher SC performance.

To identify the role of BPM and SCC, and their benefits in terms of collaborative advantage and organisational performance, terms such as business process management (BPM), supply chain management, supply chain collaboration (SCC), collaborative advantage, organisational performance and intra- and inter-organisation were used to identify relevant keywords in research papers. The following section provides the relevant literature on BPM, SCC and benefits in terms of collaborative advantage and organisational performance. The research methodology is subsequently presented, followed by the case study analysis. Finally, the key research findings are summarised and discussed, and contributions and conclusions are highlighted.

\section{Literature review}

\subsection{Business process management}

BPM has been explained by various authors [16, 17]. According to Lindsay et al. [18], BPM strives to better understand the key mechanisms of a business to improve and in some cases to radically change the business performance by identifying opportunities for new business, outsourcing, improving business efficiency and using technology within different areas of the business to support business processes. Van der Aalst et al. [17] suggested that BPM was a field of knowledge that covered the use of various methods, techniques and technologies to support business process changes, encouraging employees to become more involved. More recently, Chang [16] defined BPM as a process-oriented organisational approach used to design, analyse and improve business processes to effectively manage and improve organisational performance. In summary, BPM utilises both incremental and radical methodologies, focusing on processes, technology and the involvement of people to ensure that customer satisfaction is achieved in an effective way.

To capture the main elements of BPM, we define BPM by covering the four main elements most commonly highlighted by previous research [e.g. 16, 19]. The selection of these four elements was based on a number of citations from Harzing's (23 July 2014) "Publish or Perish". These four elements are strategic alignment, IT, process orientation and improvement and people involvement. Strategic alignment refers to long-term goals, the consideration of customer requirements and the internal characteristics of organisations and involves developing specific strategies and plans that can be implemented to maximise the value from process redesign and improvement [19]. Additionally, joint decision-making with SC partners is necessary for intra-organisational operations and the development of long-term plans. For instance, a firm and its SC partners could make joint decisions about demand forecasting and jointly establish and share common goals along a SC. IT is not developed to be used only within organisational boundaries but can also involve external IT interfaces and SC engagements. Process orientation is central to BPM and includes key elements such as process view/documentation, value stream mapping, process ownership and process measurement. BPM represents a convergence of previous process improvement approaches, as it provides information and a process management infrastructure for improvement [16, 19]. Both top management and employee empowerment need to be involved in BPM practices. Top management needs to be committed and to communicate effectively, setting organisational values and developing a suitable management style to improve organisational performance [20]. Additionally, empowering employees allows them to participate actively and creatively in their work.

Organisational performance is described as a multidimensional concept. It refers to how well an organisation fulfils both financial and market-oriented goals [21]. Financial goals are measured by figures such as sales growth, profit margin on sales and return on investment [5, 9]. Non-financial performance is measured, for example, by overall product quality, overall competitive position, overall customer service levels, core competences and capabilities [5, 9]. Non-financial performance measures can help shift attention away from short-term financial goals towards medium- and long-term goals [22].

Several studies have revealed that BPM has a positive impact on organisational performance [23-26]. However, there is limited research on the link between some attributes of BPM and organisational performance. A number of studies [19, 24] focused on the "process" concepts of BPM, its attributes and the links between attributes and benefits such as organisational performance and customer satisfaction. Smart et al. [19] empirically validated a BPM framework by considering the context of processes to characterise BPM. They identified five main dimensions of BPM, namely process strategy, process architecture, process measurement, process ownership and process improvement. Maddern et al. [24] examined the impact of BPM on service quality and customer satisfaction and highlighted that BPM is a critical factor in driving customer satisfaction. The relationship between process orientation and organisational performance was studied by Skirinjar et al. [26]. Their results showed that business process orientation leads to an improvement in both 
financial and non-financial performance. In summary, prior studies on BPM have mostly focused on some specific attributes of BPM. Hence, there is a lack of BPM research that includes all the main attributes covering the entire scope of BPM. Most studies of BPM have typically been narrowly defined and have focused on aspects within the organisational boundaries rather than investigating the link between BPM and the inter-organisational relationship.

\subsection{Supply chain collaboration}

Several researchers have indicated an increasing interest in SCC [e.g. 27, 28]. SCC occurs when two or more firms in a $\mathrm{SC}$ work closely together in planning and delivering products to end customers to optimise profits for the SC members and gain mutual benefits [5]. It is necessary to develop closer relationships, integrating processes and sharing information with customers and suppliers. According to Barratt [29, p. 33], "Internal collaboration must be married with external collaboration". Thus, firms need to collaborate in order to gain access to combinations of resources or improved capabilities that allow them to achieve collaborative advantage and higher performance. Collaborative advantage refers to strategic benefits achieved over competitors in the marketplace which could not have been achieved without working through the SC partnership [5, 30]. Therefore, these benefits achieved should be more than those achievable by a firm working in isolation. Synthesising the literature, the important elements of SCC that have been commonly used in previous research [based on a number of citations from Harzing's (23 July 2014) "Publish or Perish"] are information sharing and communication, sharing common goals, joint activities and incentive alignment [5, 28, 31]. Information sharing and communication are described as important for effective collaboration to achieve a greater shared understanding within the SC partnership; therefore, an environment of innovative thinking will be encouraged and supported [5, 13, 29, 31]. Joint activities refer to joint decision-making and the sharing of resources between SC partners. A firm and its SC partners jointly performing activities could result in the development of a deeper understanding between partners, leading to more efficient communication in a virtuous cycle. Sharing common goals is important for good relationships between firms, as they work for mutual benefits. Incentive alignment refers to the degree to which participating SC members share costs, risks and benefits [14]. It provides a system for repositioning the benefits and problems that are encountered when process changes occur within the SC.

A positive association between SC performance and organisational performance has been supported by previous studies $[6,9,21,32]$, so achieving SC performance is critical for improving firm performance. Additionally, much of the previous SCM research asserts that firms that work collaboratively with their SC partners can improve their organisational performance [5, 32-34]. SCC assists firm performance in reducing ambiguity and identifying priorities which can speed up business operations, save time and ensure that the business runs smoothly. Research by Vereecke and Muylle [33] indicated that SCC had an impact on performance improvement (in terms of delivery, cost, quality, flexibility, lead time and time to market). Thus, SC members who provide higher levels of collaboration practices (e.g. information sharing, joint activities and decision-making) were able to achieve better operational performance and innovative activities [14, 32, 34]. Also, SCC can be utilised for transferring knowledge and new technological skills across the firms, which should result in better opportunities for enhancing their objectives [5] and can lead to improved performance and competitive advantage over time. Additionally, there is evidence suggesting that SC relationships are dependent on organisational, competitive and relationship-specific attributes [3538]. The findings of Sila [35] showed that firm size did not have a great effect on the implementation of total quality management (TQM) practices. The empirical results produced by Hou [37] also showed firm size to have no significant influence on firm performance. Lavastre et al. [38] indicated that longer relationships between firms and their SC partners should result in greater mutual benefits, such as the sharing of mutual and private knowledge, and greater control over important processes through collaboration and joint learning. However, there is also a lack of empirical research elaborating on the impact of context-dependent factors on the interrelationship between the competitive and performance linkages, on both the individual operation and the SC.

\subsection{Intra- and inter-organisational management practice}

Unlike previous research, which has tended to focus on BPM and SCC separately $[6,11]$, this study summarises the link between BPM and SCC, as presented in Fig. 1. A framework has been developed based on a review of the relevant literature to identify the link between intra- and inter-firm management practices. In terms of internal collaboration, as represented by BPM, this ultimately incorporates four main attributes: strategic alignment, IT, process orientation and improvement and people involvement.

SCC emphasises external collaboration, and this incorporates four main attributes, namely information sharing and communication, joint activities, sharing common goals 
Fig. 1 Relationship between $\mathrm{BPM}, \mathrm{SCC}$ and the performance outcomes

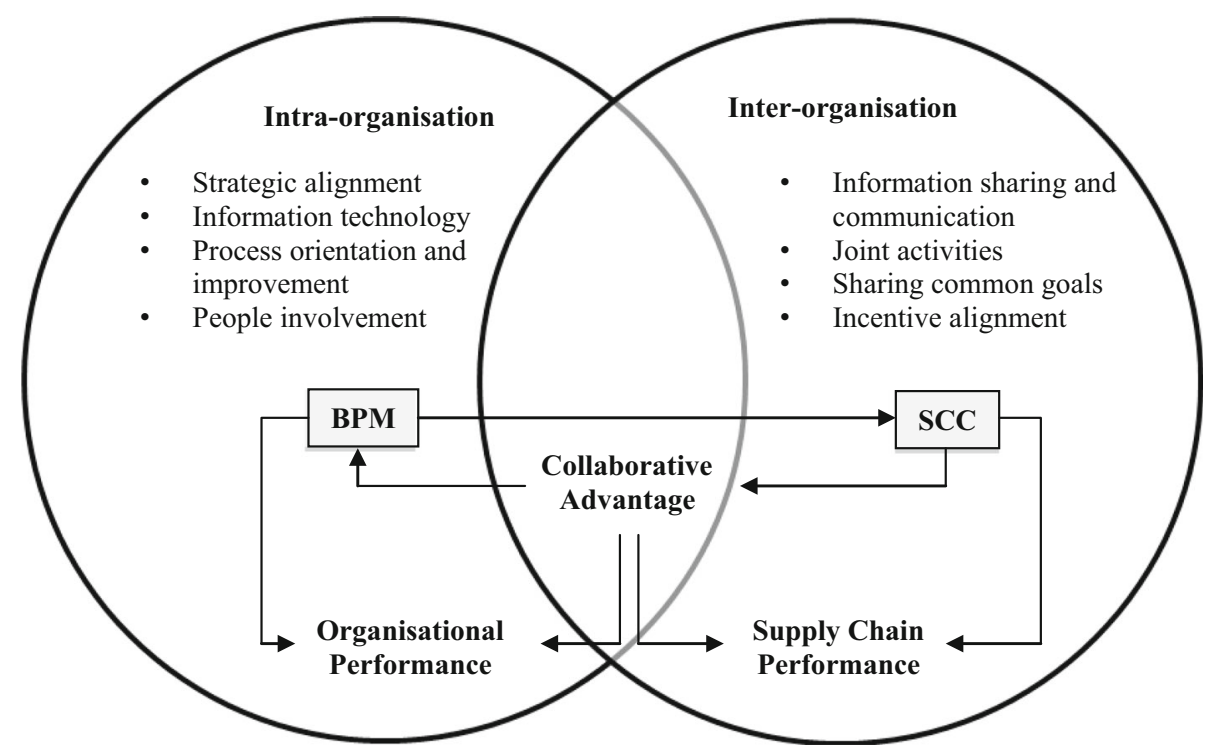

and incentive alignment. Effective internal development and working collaboratively with SC partners should result in superior performance, at both firm and SC levels. Firms that practice BPM and also collaborate with SC partners develop collaborative advantage, which cannot be achieved when they work individually. Collaborative advantage, in turn, leads to improved internal capabilities and organisational performance. Therefore, the presence of a virtuous cycle is suggested.

Consequently, a taxonomy was developed (see Fig. 2) to map the links between BPM and SCC and benefits achieved in terms of SC performance, which can lead to improved firm performance. Of the different SC levels, this research focuses exclusively on direct SC relationships in which a firm is working collaboratively with its suppliers or customers, so the taxonomy consists of two dimensions: the level of internal development, represented by BPM, and the level of external development, as influenced by SCC. A combination of these two dimensions classifies four types of relationships, and this interaction results in different levels of performance outcomes.

The "Star performance" quadrant A represents the state where all firms within a SC emphasise high internal development (high BPM), as well as a high level of collaboration with their SC partners (high SCC). This state is achieved, typically, in an effort to effectively differentiate themselves from their rivals and/or reduce costs along the SC. High internal and external development can be achieved by integrating processes and sharing information with customers and suppliers. Companies collectively
Fig. 2 Different styles of internal and external collaboration

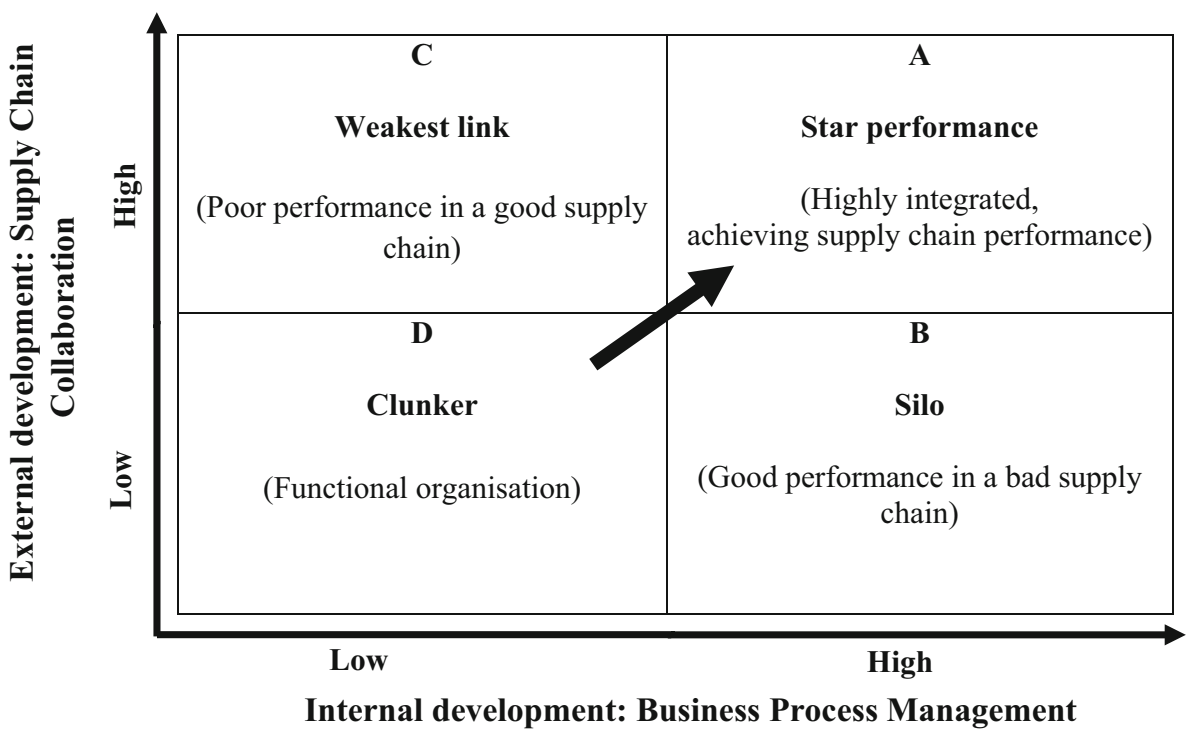


achieve higher levels of SC performance by instigating holistic SCM. Therefore, firms in this quadrant need to closely monitor the effectiveness of internal and external development in order to justify relevant efforts and maintain their relative competitive positions [14, 29].

The "Silo" situation B represents the state of a firm within a SC that demonstrates high BPM and low SCC. A high level of internal development is achieved when a firm completes integrated tasks across various internal boundaries, such as purchasing, manufacturing, logistics and marketing. This position can be achieved by using advanced technology and/or by using process improvement programmes such as TQM, just-in-time (JIT) and ERP to optimise the silo (i.e. the individual company) rather than optimising the whole SC. Nowadays, a narrow view that only focuses within an organisation is not considered adequate [39]. A firm that pays little attention to working collaboratively with its SC partners and does not align its business strategy to the SC strategy may experience a loss of opportunity to improve its performance [40]. Therefore, firms in this position need to collaborate with their SC members to achieve effective responses to customers' needs [41] by jointly forecasting and planning, otherwise, they may lose their relative competitive positions and fail to achieve the star performance.

The "Weakest link" quadrant C represents the state of a firm within a SC that emphasises low BPM and high SCC. In many cases, close relationships between a firm and its SC partners exist, but often the firm is resistant to open information sharing [42]. Incomplete or insufficient information sharing to support collaboration will probably reduce the opportunity for a high level of collaboration between a firm and its SC partners [42]. Additionally, this position can occur when a firm perceives some costs in contending with their partners' threats [14]. Firms in this position need to improve their internal capabilities such as technology and innovation development and the use of process improvement techniques in order to collaborate with SC members effectively and to achieve better performance. Otherwise, their future membership in the SC may be in jeopardy.

The "Clunker" quadrant D represents the state of a firm within a SC emphasising low BPM and low SCC. Here, companies exhibit low levels of internal and external integration, which are typical of a SC containing many functional organisations. It can be presented as a "traditional supply chain" [43, p. 172], whereby each level in the SC issues production orders and replaces stock without considering the situations of suppliers and customers in the SC. Therefore, the SC exhibits low formal collaboration between firms. Overall, firms in this position may lack a common SC perspective in terms of internal and external development.
In relation to the previous, resource-based view (RBV) and relational view (RV) are appropriate for the theoretical explanation of the relationships between intra- and interfirms and the outcomes that can be achieved from the relationships investigated [e.g. 5, 11, 27, 44]. RBV is concerned with how a single firm can generate competitive advantage results based upon resources and capabilities that are owned and controlled within a firm [45]. It is focused on the internal organisation, and it is a complement to both the traditional emphasis of strategy on industry structure and strategic positioning as keys to competitive advantage [46]. RBV can be used to provide a theoretical background for evaluating types of internal capabilities that offer a competitive advantage which can lead to improvements in financial performance [47]. Ultimately, BPM resources (e.g. the use of IT, process orientation and improvement, people involvement and employee skills development) may form unique capabilities for competitive advantage. Hence, these resources can be utilised to contribute to the firm's success in current and future markets.

$\mathrm{RV}$ focuses on the dyad/network rather than on individual firms [11, 44, 45, 48]. Thus, RV explains the role of collaboration as a way to develop complementary capabilities in order to achieve competitive advantage [11,44]. $\mathrm{RV}$ indicates that organisational capabilities can be developed by spanning the boundary of firms through the combination of resources from different firms in the SC. SCC and collaborative advantage are based on the RV theory, which takes into account the dyad/network, instead of individual firms, as the unit of analysis. Thus, it provides the mechanism of joint value creation, such as inter-firm rent generation $[11,27]$.

\section{Methodology}

This study employed the case study approach as a followup to the large-scale survey $[49,50]$ to gain a deeper understanding of the empirical results. Regarding the case study selection, a multiple case design was adopted to further elaborate on the quantitative findings. This design is derived from diverse types of conditions and aims to have sub-groups of cases covering each type [49]. The case selection process was based on the criteria of size and industry: one medium- and one large-sized firm from the automotive and electronics industries. The size distinction was based on the official Thai definition: a medium-sized firm having 51-200 employees and a large-sized firm employing more than 200 people (The Ministry of Industry Thailand, 2013). This process allowed for some level of triangulation above the company level [49]. Overall, 15 firms meeting these criteria, which contributed to the first phase of the study, were selected and contacted via email 
and by phone. Finally, four cases were selected to participate in the interview process. The selected paradigmatic case studies allowed for a comparison of similarities and differences between firm size, industry type, relationship direction and relationship length. The identities of the companies have to remain anonymous because of confidentiality agreements, and they are referred to as follows (see also Fig. 3): ELC (a large electronics company), $A L C$ (a large automotive company), EMC (a medium-sized electronics company) and $A M C$ (a medium-sized automotive company). Appendix 1 provides the backgrounds of the participating companies.

An interview protocol was developed, based on the results of the large-scale survey, to ensure that all issues required were addressed. The interview questions were organised in a logical sequential order, with wording that was not too direct and too leading, resulting in clear and precise questions to ensure that the interview questions were effective [51]. Appendix 2 elaborates on the development of the interview questions. In relation to subquestion 1 (see Sect. 1), the interview questions asked participants to describe BPM and its practices, how BPM has helped to improve organisational performance, relationship difficulties and the solutions for dealing with challenges. In relation to our second research sub-question (see Sect. 1), the interview questions asked how BPM has helped collaborative activities, whether the firms had experienced relationship difficulties and what solutions have been implemented to address such challenges. In relation to our third research sub-question, the interview questions focused on relationship characteristics (i.e. the closeness of the relationship, the reasons for engaging the company in collaboration, relationship difficulties, solutions to the challenges and relationship length), as well as benefits that the company has achieved from working collaboratively with its SC partner, challenges to achieving collaborative advantage and solutions implemented to address such challenges. Additionally, questions covered how collaborative advantage has helped to improve organisational performance and what would happen if a company operated without a collaborative relationship.

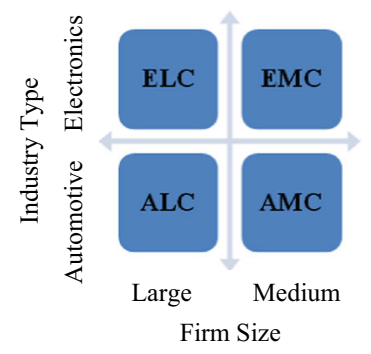

Fig. 3 Case study selection
After careful development, the interview protocol was translated into Thai. Then, the interview protocol was pilottested to assess whether it was workable and to identify any problems that might occur during the subsequent interview process.

Semi-structured interviews were employed between February and mid-March 2014. From each of the four companies, the member of personnel who had completed the large-scale survey was contacted. Interview questions were sent to the practitioners 3-5 days in advance to allow them time to prepare their answers to the interview questions. The average duration of each interview was one and a half hours. All interviews were digitally recorded, and field notes were also used to collect information during the interview. The voice recordings of the interviews were later transcribed into Thai and then translated into English. A case study database was developed and used for visualising the data and for developing tables and matrices containing various views used in the case study analysis.

The case study data analysis followed "the data analysis spiral" suggested by Creswell [52, p. 150]. The processes move along with the analytical circles in a nonlinear approach, touching on several facets of analysis and circling around and around [52]. The analysis procedures include: (1) data managing; (2) reading and memoing; (3) describing, classifying and interpreting; and (4) representing and visualising. The first task in the spiral begins with organising the data into an assessable format ("data managing" procedure). Then, further notes were made to record the key ideas and concepts during the reading of the interview database ("reading and memoing" procedure). After scanning through the database, "conceptually clustered matrices" were developed ("classification" procedure). The development of conceptually clustered matrices is the most useful technique when: (1) a clear concept or theme has emerged from the initial analysis or (2) during early analysis, and after reading through the transcripts, the researcher finds that participants have given very similar or vastly different responses to questions and that unexpected variables, concepts, and themes have emerged [53]. In addition, rows and columns were created to bring research sub-topics, concepts and/or themes together, developing a summary documentation and analysis [53]. The conceptually clustered matrix ensures all the data fit into a reasonable format. It also presents a set of themes with information of each case, which lends itself to cross-case analysis for multiple case studies [53]. In this study, the main themes developed based on the research questions were: (1) the link between BPM and organisational performance; (2) the link between BPM and SCC; and (3) the contextual factors and benefits achieved from working collaboratively with SC partners. Additionally, some sub-themes (e.g. BPM regarding activities and solutions for short-term relationships) were identified at an 
early stage of the data analysis, as the participants provided similar explanations. The transcripts from the interviews were entered into the matrix based on specific themes and sub-themes that had been identified. The case study database is developed and an information summary of each case is shown in a table format ("representing" procedure, the final phase of the spiral) (see Appendix 3). This table displays all of the relevant responses of all cases and allows initial comparisons for the cross-case analysis.

\section{Case study analysis}

\subsection{A summary of the within-case analysis}

A summary of the within-case analysis is shown in Appendix 3. The table covers the link between BPM and organisational performance, the link between BPM and SCC, the benefits of working collaboratively with SC partners and organisational performance. Additionally, the table includes the contextual factors of relationship closeness and relationship length for each case company. A summary of the four cases aided the cross-case analysis that is presented in the following sections.

\subsection{Cross-case analysis}

\subsubsection{The link between BPM and organisational performance}

We asked each respondent to describe BPM from a practitioner's perspective. All cases provided four common characteristics of BPM practices, namely long-term planning, IT, process improvement, and top management support and employee involvement. Long-term planning needs to be based on customer requirements and should cover aspects of production planning, promotional events and supplier development. This plan has to be jointly developed with the SC partners. For instance, the Production Manager from ALC suggested that:

The company has set a long-term policy, which is for three years. However, at the end of each year there is a review of the situation, and if necessary there is a change to or an improvement to the plan. The company has jointly developed production forecasts with its suppliers.

These long-term plans have to be integrated into the companies' operational processes. Additionally, the case study results indicated that joint decision-making with SC partners is necessary for intra-organisational operations and the development of long-term plans, so that the latter are aligned with those of their SC partners. IT is important to accomplish the business plan and to improve operational processes, and IT is used to share information both within an organisation, from top management to employees, and with their SC partners. For instance, it was suggested that:

The use of IT is very important to accomplish this plan, and information sharing includes both top management and all the employees. (ELC)

All cases underlined the importance of IT being developed not only to be used within organisational boundaries but to also involve external IT interfaces and SC engagement. This allows information to be shared between different departments within the company to improve its products and processes, meaning that necessary information can be shared easily with SC partners, such as specific product requirements and demand forecasting. The four cases have used various process improvement techniques such as TQM, Lean Manufacturing and Kaizen to improve their business processes. The managers pointed out that their process improvement techniques were often the same techniques as their SC partners (ALC, EMC and AMC). The use of process improvement techniques also leads to more employee involvement; for instance, it was suggested that the use of Kaizen provides opportunities for employees to contribute any suggestions they may have for work improvements (ELC). The effective use of process improvement techniques is vital for optimising processes and maximising value for an organisation. Top management support is very important for successful BPM practices, as participants in all four cases suggested that their BPM practices were fully supported and led by top management. Additionally, good relationships between top management and employees have been developed. For instance, one company provides a "President box" for employees to contact the president of the company directly (ELC). Additionally, employees are involved in decision-making; it was reported that:

Top management has to set policies that should lead to improvements. However, before the policies have been set, there is an internal meeting, including managers of each department, where they discuss any problems. Also, employees can give any suggestions they have to their manager. (ALC)

We have sent employees to train in Japan to learn new technology and innovations, so they can come back to improve our products. (ELC)

Thus, employees have opportunities to learn new technology to improve products to meet customer requirements. The four participants explained that BPM practices 
had helped to improve their organisational performance, both financial and non-financial. In terms of financial performance, all four cases emphasised that sales growth and cost reduction were the most important dimensions. Sales growth and cost reduction referred to the improvement in production processes, the policies adopted to reduce costs and the reduction in waste. It was explained that:

In terms of cost reductions, the company has set targets for cost reductions, improved sales growth and improved product quality in each department. (EMC)

Regarding non-financial performance, two cases focused on overall competitive position and core competences (ELC and ALC). For all cases, quality is an important issue. The four companies have continued to carry out quality improvement activities such as recording problems and the improvements and preventive measures in response to quality non-conformity and the monitoring of progress. Waste reduction was also important for all cases.

\subsubsection{The link between BPM and SCC}

From our investigation, BPM practices help various collaborative activities, which can be divided into four types: information sharing and communication, joint activities, sharing common goals and sharing costs, risks and benefits. The analysis provided evidence of the importance of information sharing and communication within a firm and with SC partners. For instance, an ERP system is used to share information within the company and with its SC partners for a long period of time $(>20$ years for ELC and 5-10 years for ALC). Technical and non-technical information is also shared with suppliers (ALC). In addition, all four managers explained that relevant knowledge regarding collaborative activities and process improvements is shared between a firm, suppliers and customers. For instance, knowledge regarding process improvement techniques and knowledge that can be used to reduce costs in the production process are being shared. The factory manager from AMC indicated that:

A customer sent a team to our company so they could share their knowledge about some process improvement techniques, such as the TPS [...], so now the firm and our customers are using the same techniques to mutually improve our businesses.

Also, all cases indicated the importance of open and clear communication, both formal and informal, with suppliers and customers. For example, informal communication is used (ELC and ALC) in crucial situations when a manager is not in the office to sign an official document. Staff can make telephone calls to order raw materials before using the more formal method of sending official documents (ELC). A specialised voice and messaging application is used for informal communication to update information between a firm and its suppliers (ALC). All cases have some form of joint activities with their SC partners, for instance, jointly planning demand forecasts, resolving forecast errors and jointly working out solutions to problems within a SC. Regular meetings with suppliers and customers are held to jointly plan and jointly solve problems and to update any changes and improvements in terms of production planning, process improvement and technology. For instance, case ALC has set up a team to work closely with its suppliers to improve and develop the relationships and grow together. It is important for working collaboratively with SC partners that mutual benefits are highlighted (all cases). The Production Manager in case AMC stated that:

If there is no agreement about goals and objectives from working collaboratively, this could create problems rather than benefits within the chain.

All of the managers also explained that a firm, suppliers and customers need to develop and grow together. A firm has also co-developed systems by setting and sharing key performance indicators (KPIs) together with its suppliers (ALC). Taking into account the joint activities and the sharing of mutual benefits between a firm and its SC partners, the case studies results show that all cases have some form of sharing cost, risk and benefit with their SC partners. For instance, ALC has systems which have been co-developed through jointly setting and sharing KPIs. The production plan also requires SC partners to be involved in terms of demand forecasts and promotions. The SC Manager made this point:

This production plan also needs the SC partners to be involved. There has to be a sharing of costs, risks and benefits because, if not, then it is not a concept of SCC. (ELC)

The four cases illustrate that an intra-organisational focus (on BPM) is a prerequisite for inter-organisational activities (SCC). The managers in all cases suggested that working collaboratively with SC partners would be paid back to the company in terms of benefits along the SC, and this can help to improve the firm performance. The Production Manager from case ALC suggested that:

To collaborate successfully with SC partners, firstly, we have to improve and develop both human resources and technology. Secondly, we have to drive the growth of our suppliers at the same time as our company. Thirdly, we have to follow the "voice of the customer" as much as we can, in order to meet 
customer requirements and to achieve customer satisfaction. Finally, these three will be paid back to the company in terms of mutual benefits along the SC, and this must help to improve our firm's performance.

Overall, the case studies offer detailed explanations with regard to how the firms collaborate with their SC partners in terms of information sharing and communication, joint activities, sharing common goals and the sharing of costs, risks and benefits.

\subsubsection{Contextual factors and the relationship benefits}

The interview participants explained the mutually beneficial outcomes of BPM practices and working jointly with SC partners in terms of collaborative advantage and organisational performance, as summarised in Fig. 4. This figure highlights similarities and differences between the contextual factors of firm size, industry type and relationship closeness, contributing to our cross-case analysis. Regarding collaborative advantage, the initial terms from the case studies are time to market, quality and meeting customers' requirements. The Production Manager in ALC explained that:

Time to market and quality are essential because we produce automotive parts, which means that if the car is sold, then we will automatically hit the market. The others are product variety, meeting customers' requirements, using technology and innovation effectively and sharing system controls with customers, which we can use in our own company.

The results from the case studies also illustrate that working collaboratively with SC partners improves both financial (cost reduction, sales growth and return on investment) and non-financial (quality, overall competitive positions and waste reduction) organisational performance (all cases). For instance, the SC Manager in ELC indicated that:

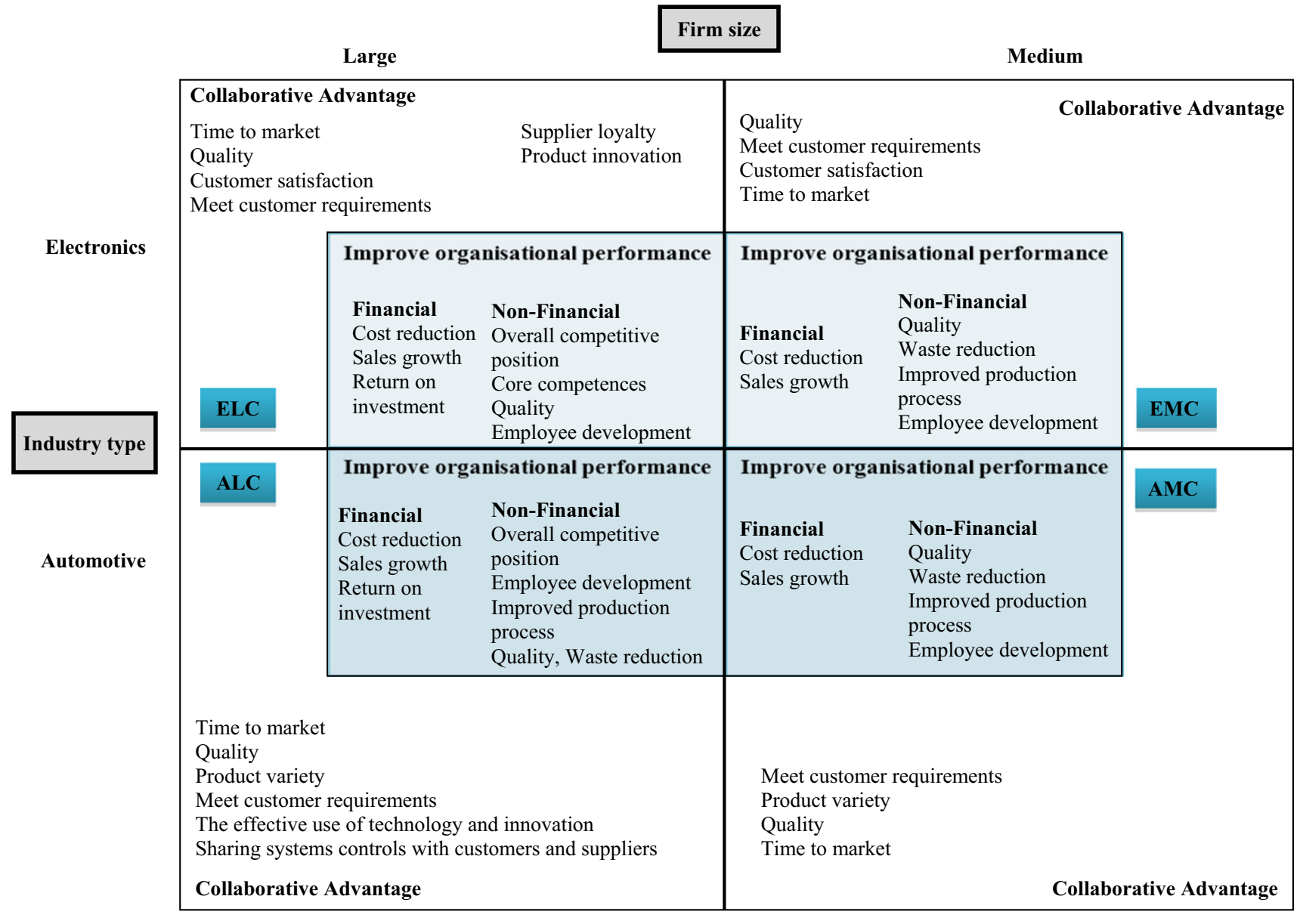

Suppliers

Customers

Fig. 4 Benefits from working collaboratively with SC partner 
This has created a win-win situation for the company, customers and suppliers. The collaboration has resulted in the suppliers knowing that they will receive orders from the company, as long as they maintain certain standards, and everyone benefits from working collaboratively.

Therefore, firms that focus on their internal development by practising BPM and that collaborate with their SC partners can achieve a collaborative advantage, which in turn leads to an improvement in organisational performance, both financial and non-financial. The results also indicate that large firms work more closely with suppliers, whereas the medium firms work more closely with their customers. The results show that regardless of firm size, similar collaborative advantage can be achieved. However, firm size is important when the priorities of collaborative advantage are taken into account. The two large firms focus more on time to market and quality, while the mediumsized firms concentrate more on quality and meeting customer requirements. The results indicate that product innovation and the effective use of technology are the main focus in the large firms and that they are actively improving their technology and their employees' skills to facilitate these outcomes. All four companies suggested that the relationship direction is usually based on long-term partnerships.

Additionally, whether the company is working closely with suppliers or customers, both need to work jointly; for example, it is important to have joint meetings to develop policy, joint decision-making, joint problem-solving, joint planning of demand forecasts and joint efforts to reduce lead time with suppliers. In relation to the importance of close relationships with SC partners, two practitioners explained that:

The use of technology and joint activities such as forecasting with suppliers is vital. Also, the company visits suppliers and attempts to solve production problems together. (ELC)

The activities with close suppliers cover developing policy and technology together, sharing information and sharing knowledge such as product design. (ALC)

As regards industry type, the results show that the electronics and automotive industries are similar in the way they collaborate with SC partners. Both electronics and automotive industries provide similar results in terms of benefits achieved from working collaboratively with their SC partners. However, the two automotive companies focus more on improving product variety. It was explained that:

We need to develop technology to support the new automotive models [...]. The company sees innovation as a way to improve our products so that they have a longer life [...] we have to improve our employees' skills so that we can use new skills to improve current products and to provide innovative products. (ALC)

Regarding the relationship length, the results show that the four cases have been working collaboratively with their closest SC partners since they started the business, over a period of between 10 and 22 years. All participants suggested that long-term relationships incurred fewer problems, provided more flexibility and allowed communication to be both formal and informal. In contrast, short-term relationships tend to be more complex, as they are more difficult in terms of price negotiations and more time-consuming in terms of communication. For example, the Production Manager in AMC stated that:

Communication is easier than when it's a short-term relationship $[. .$.$] we rely on each other more.$

Dealing with short-term relationships is more complex. Although the results reveal that short-term SC relationships can create difficulties, they do not have an impact on the benefits achieved from collaborative advantage and organisational performance. The managers highlighted that:

Actually, the length of the relationship does not cause any problems in terms of benefits, but shortterm relationships make the collaboration process more complicated than long-term relationships do. (ALC)

Relationship length has not caused any problems because we are continuously improving our systems. However, it is not about relationship length, it is more about how to improve our business so that we are able to compete in the market better than our competitors. (EMC)

\section{Key findings and discussion}

Based on a specific context of Thailand manufacturing sectors, the results from the case studies have illustrated the key common characteristics of BPM, which are long-term planning, IT, process improvement, top management support and employee involvement. These common characteristics can assist a firm in improving organisational performance, both financial (e.g. sales growth and cost reduction) and non-financial (e.g. quality and waste reduction). This finding is in line with the vast majority of previous research in which a positive relationship between 
BPM and organisational performance has also been found $[15,23-26]$. The results from the case studies offered explanations about how the firms practice BPM, as well as about the importance of BPM practices in improving organisational performance (see Sect. 4.2.1). This supports the RBV theory [45-47], according to which resources and practices that are developed within a company can contribute to a firm's performance and are difficult for competitors to imitate.

It has been established that an intra-organisational focus (BPM) is essential for inter-organisational activities (SCC) in terms of information sharing and communication, joint activities, sharing common goals and sharing costs, risks and benefits. A firm and its SC partners need to develop and grow together and work to enhance their mutual benefits. The results reveal that BPM not only improves organisational performance directly, but also assists with collaborative activities that in turn help to improve internal capabilities. This finding is, to some extent, consistent with $[6,9,13,15]$, which highlight the importance of intra- and inter-organisational development for business success and competitive advantage. The results of this study make it more explicit in terms of how intra-organisational focus (BPM) is essential for inter-organisational activities (SCC) (see Sect. 4.2.2). The results support the RV theory [11, 44], according to which firms need to consider leveraging their resources with their SC partners in order to gain more competitive advantage. Firms working together with their SC partners to share their knowledge and skills and combine their resources can create greater capabilities than firms working individually.

The case studies illustrate that the benefits of working with SC partners are related to collaborative advantage and organisational performance. Also, they illustrate the practices and approaches taken across diverse firm sizes and industry types and the effects of the closeness and length of relationships. Firms of different sizes can contribute proportional financial and managerial resources to support their collaborative efforts; however, the firms were found to develop appropriate strategies with their SC partners based on common goals and the sharing of their, occasionally limited, resources in an effective way, thus achieving collaborative advantage and improving organisational performance. Additionally, they were found to apply different business strategies. For example, the medium-sized firms tended to focus only on cost reduction and sales growth, whereas the large firms additionally looked at their overall competitive position. This finding is, to some extent, consistent with [15, 35, 37]. Our research develops explicit knowledge linking BPM, SCC and the benefits in medium firms compared to large firms (see Sect. 4.2.3).
The case studies provided a greater understanding of how firms of different sizes, from both the electronics and automotive industries, have chosen to work closely with their SC partners in different ways. The larger firms are working more closely with their suppliers, while the closest relationships the medium-sized firms have are with their customers. The closest partnerships are characterised as being of a long-term nature, with firms working closely together in various activities such as planning, decisionmaking and sharing knowledge over time. As regards the length of the relationships, long-term relationships between a firm and its SC partners result in fewer problems, enhanced flexibility and open communication. This is in line with previous research $[36,38]$. Nevertheless, the case study analysis shows that short-term relationships can be difficult (e.g. in terms of communication and the setting of policies and conditions) but do not have any impact on the benefits achieved in terms of collaborative advantage and organisational performance. Hence, collaborative relationships, whether long or short term, result in mutual benefits and improved organisational performance.

Based on the above results, the practices of these four companies can be categorised into different scenarios in relation to the link between BPM and SCC. Employing the discussion in Sect. 2.3, we can now map all case studies according to the level of internal and external development, as presented in Fig. 5. The companies in the cases ELC and ALC can be identified as "Silo" cases because they have highly integrated tasks across different departments within their organisations. Additionally, advanced technology has been used to support their internal and external developments.

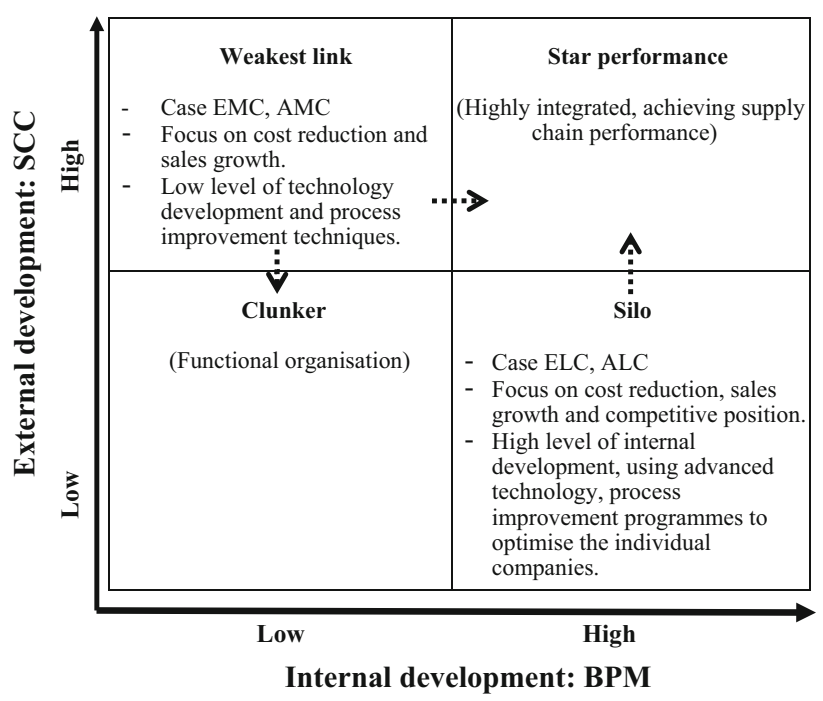

Fig. 5 Internal and external collaboration and the case study results 
Both ELC and ALC place an emphasis on technology and innovation, as these have been used to improve quality, safety and production processes. Also, ERP systems have been used by these two companies for a long period of time (>20 years for ELC and 5-10 years for ALC) to share information both within the companies and with their SC partners. Various process improvement techniques have been used to improve their business processes, such as TQM, BPR, Lean, Six Sigma and Kaizen. The two companies have focused on cost reduction, sales growth and their competitive positions and consider the use of technology to be very important for new product development. Therefore, working closely with their SC partners to share knowledge, jointly develop and share KPIs, and align company strategies with SC strategies should result in a high level of integration and better SC performance.

The other two companies (EMC and AMC) employ process improvement techniques but have used them for less time than the large firms ("weakest link" cases). For instance, they have used TQM, Lean and Kaizen for between 5 and 10 years. Also, there is less focus on improving production technology (compared with the two large firms). For example, they provide their employees with initial basic skills, but tend not to provide them with more advanced knowledge of new technology. Additionally, these two companies are mainly focused on cost reduction and sales growth rather than improving their competitive position. Therefore, the internal capabilities of these two case companies could be developed through the improvement in their technology, innovation development and the use of process improvement techniques that would help them collaborate with their SC partners more effectively. This should result in enhanced performance; otherwise, they might not be able to continue to justify their membership in the SC to the other members.

\section{Contribution}

\subsection{Theoretical contributions}

From a theoretical perspective, RBV and RV are foundations that expand understanding of the links between BPM, SCC, collaborative advantage and organisational performance. This study's results provided support for both RBV and RV theories. Drawing upon RV, it was proposed that firms which collaborate with SC partners will achieve more benefits than when they work in isolation. Indeed, previous research has suggested that both BPM and SCC are vital for performance improvements and competitiveness [1114, 31]. However, these two approaches have been studied separately. The main contribution of this paper is to provide a deeper understanding of "How" and "Why" BPM and SCC interrelate to drive collaborative advantage and organisational performance. Also, the results from the case studies provide in-depth views that BPM contributes directly and indirectly to the improvement in organisational performance. A matrix is proposed based on a literature review to capture the different situations exhibited within SCs, considering internal and external development, and different types of relationships between BPM and SCC are identified within the configurations being distinguished.

The study added to the limited empirical research concerning the impacts of contextual factors on the interrelationships between the competitive and performance linkages, at both internal company and SC levels. A number of previous studies have indicated the importance of contextual factors [12, 15, 35-39]. However, there is a lack of empirical research describing the impact of contextual factors on the links between BPM and SCC. In addition, this is the first research of its kind that has studied the links between BPM, SCC and the benefits which can be achieved from these links within the context of Thailand's manufacturing industries. A detailed understanding of each contextual factor in terms of firm size, industry type, closeness and relationship length was gained. Also, the important manufacturing industries, namely the automotive and electronics industries in a developing economy, Thailand, were addressed in this study. Arguably, this study is vital for the future growth and development of Thailand's manufacturing industries, and with some adjustments, it could be used in other countries whose manufacturing sectors share similar characteristics with Thailand.

\subsection{Practical contributions}

Based on the research findings, there are practical implications relevant to organisations wishing to extract further value from working collaboratively with their SC partners and from their BPM practices. Firstly, this research can assist management to be conscious of the importance of the intra- and inter-organisational development, given that the premise of BPM is to improve organisational performance and to support collaborative activities. Therefore, management should take into consideration that the internal development based on BPM practices does not only improve organisational performance, but also that BPM is crucial for collaborative activities between a firm and its SC partners. Similarly, this study can expand management's awareness about the multi-dimensional nature of BPM, and the particular importance of its four key elements, namely strategic alignment, IT, process orientation 
and improvement, and people involvement. Furthermore, managers should consider collaborating by sharing information (and communicating), performing joint activities and sharing common goals, costs, risks and benefits, which will enable firms to effectively leverage their capabilities and to accomplish the desired benefits.

Secondly, the different scenarios of the link between BPM and SCC that were identified in a taxonomy presented as a $2 \times 2$ matrix (see Fig. 2) can also assist practitioners in mapping the portfolio of the various SCs in which they are embedded. The lessons drawn from the case studies incorporate practical mechanisms of BPM and SCC approaches that are critical to offering benefits in terms of collaborative advantage and organisational performance. Collaboration with SC partners has to be regarded as vital for competing in the market due to the fact that improving the effectiveness of SC relationships enables the creation of rare and valuable capabilities, allowing higher performance levels than those that could be achieved when working individually. Therefore, management should not consider BPM and SCC as separate. Our research highlights how and why BPM and SCC have to be implemented together to achieve superior performance in the intra- and interorganisational relationship context.

Thirdly, according to our results, managers should consider that the four contextual factors under investigation have a minor impact. This means that BPM practices based on the four common features of long-term planning, IT, process improvement and top management support and employee involvement and working collaboratively with SC partners can lead to benefits in terms of collaborative advantage and organisational performance even when firms have different characteristics. Nevertheless, managers should consider allocating sufficient efforts in terms of resources and employee skills to convince SC partners to implement more collaborative activities. Lastly, our results inform on practices in a developing economy context (that of Thailand); they should be of high relevance to companies' management involved or aiming to be involved directly or indirectly in operations in such an economy context.

\section{Conclusions and future research}

This paper provides a deeper understanding of the interrelationships between BPM, SCC, collaborative advantage and organisational performance. Four case studies were selected to participate in semi-structured interviews to offer a greater understanding about the relationships under study. Therefore, the reasons behind the results of the relationships between BPM, SCC, collaborative advantage and organisational performance are explained. The main issues of: (1) the link between BPM and organisational performance; (2) the link between BPM and SCC; and (3) the contextual factors and benefits achieved from working collaboratively with SC partners were explored to understand the actual practices of BPM and SCC.

It is acknowledged that there are limitations of the study. Firstly, the data collection was based on a few individual firms. Future research could consider extending this research by collecting and examining these relationships by using a wider sample to compare the differences and similarities to gain a comprehensive understanding within each industry type. Secondly, the data collection was based on one key respondent per company. Future research may consider using a broader range of respondents from different positions to achieve a greater understanding of the company's BPM practice, its collaboration with SC partners and the benefits achieved. Lastly, the study is scoped at specific industry types and limited on the considerations of the contextual factors. Therefore, future research could consider other industry sectors and other contextual factors (e.g. type of ownership) in order to identify the relationships between BPM, SCC, collaborative advantage and organisational performance.

Open Access This article is distributed under the terms of the Creative Commons Attribution 4.0 International License (http://crea tivecommons.org/licenses/by/4.0/), which permits unrestricted use, distribution, and reproduction in any medium, provided you give appropriate credit to the original author(s) and the source, provide a link to the Creative Commons license, and indicate if changes were made. 


\section{Appendix 1}

Summary of the companies' profiles

\begin{tabular}{|c|c|c|c|c|}
\hline \multirow[t]{2}{*}{ Company details } & \multicolumn{2}{|l|}{ Large firms } & \multicolumn{2}{|l|}{ Medium firms } \\
\hline & Company ELC & Company ALC & Company EMC & Company AMC \\
\hline Type of products & $\begin{array}{l}\text { Elevators } \\
\text { Escalators } \\
\text { Moving walkways }\end{array}$ & $\begin{array}{l}\text { Automotive and } \\
\text { motorcycle batteries }\end{array}$ & $\begin{array}{l}\text { Electrical components inverters, switch } \\
\text { boxes and wire harnesses }\end{array}$ & $\begin{array}{l}\text { Automotive parts } \\
\text { Electric household } \\
\text { appliances }\end{array}$ \\
\hline $\begin{array}{l}\text { Number of } \\
\text { employees }\end{array}$ & 2200 & 600 & 120 & 101 \\
\hline Ownership & $100 \%$ Japanese & $100 \%$ Japanese & $\begin{array}{l}\text { Joint venture: Japanese } 94.33 \% \text {, Thai } \\
5.67 \%\end{array}$ & 100 \% Japanese \\
\hline Certification & ISO 9001: 2008 & ISO 9001: 2008 & ISO 9001: 2000 & ISO 9001:2008 \\
\hline $\begin{array}{l}\text { Process improvement } \\
\text { techniques }\end{array}$ & $\begin{array}{l}\text { TQM }>10-20 \text { years } \\
\text { BPR }>10-20 \text { years } \\
\text { ERP }>20 \text { years } \\
\text { Lean }>5-10 \text { years } \\
\text { Six sigma } \\
>10-20 \text { years } \\
\text { Others: balanced } \\
\text { scorecard, Kaizen }\end{array}$ & $\begin{array}{l}\text { TQM }>1-5 \text { years } \\
\text { BPR }>1-5 \text { years } \\
\text { ERP }>5-10 \text { years } \\
\text { Lean }>5-10 \text { years } \\
\text { Six sigma }<1 \text { year } \\
\text { Others: TPS, balanced } \\
\text { scorecard }\end{array}$ & $\begin{array}{l}\text { TQM }>1-5 \text { years } \\
\text { Lean }>5-10 \text { years } \\
\text { Others: e.g. PDCA, Kaizen, specific system } \\
\text { of the company }\end{array}$ & $\begin{array}{l}\text { TQM >1-5 years } \\
\text { Others: e.g. TPS }\end{array}$ \\
\hline Job title of participant & SC manager & Production manager & Department manager & Factory manager \\
\hline
\end{tabular}

\section{Appendix 2: Interview protocol}

The interview protocol consisted of two main parts: the introduction and the semi-structured interview questions. The introduction part of the interview protocol covered the research objectives and a brief summary of the outline results from the large-scale survey to guide the respondents regarding the purpose of the interview. The second part includes the interview questions, which are broken down into six sections. The first section covered questions regarding general information of the company such as company name, the number of employees, and the industry sector to which the company belongs. The second section focused on BPM practices and benefits in terms of organisational performance. The development of the questions includes a description of BPM from a practitioner's perspective, how BPM has helped to improve organisational performance, relationship difficulties and the solutions for dealing with challenges. The third section explored the relationships between BPM and SCC. The questions covered how BPM has helped collaborative activities, relationship difficulties and solutions to the challenges. Section four dealt with contextual factors of the main SC partner. The questions focused on relationship characteristics, which included the closeness of the relationship, the reasons for engaging the company in collaboration, relationship difficulties, solutions to the challenges and relationship length. Section five focused on benefits achieved from working collaboratively with SC partner(s). The questions included benefits that the company has achieved from working collaboratively with their SC partner, the challenges to achieving collaborative advantage and solutions to the challenges. Additionally, questions covered how collaborative advantage has helped to improve organisational performance and what would happen if a company operated without a collaborative relationship. Lastly, a clean-up question was asked which allowed practitioners to give their opinions on what they regarded as important issues which were not included in the interview questions. 


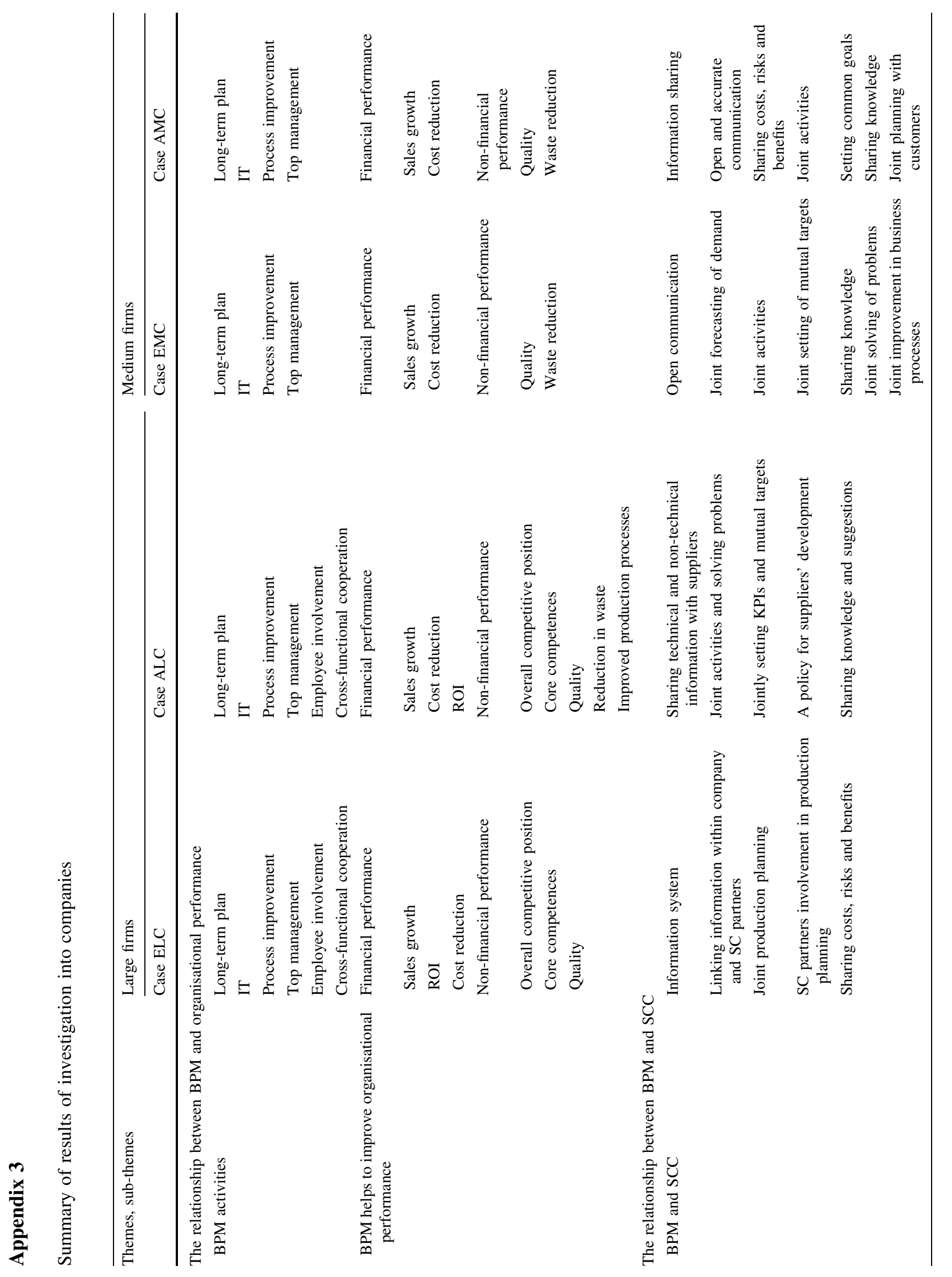




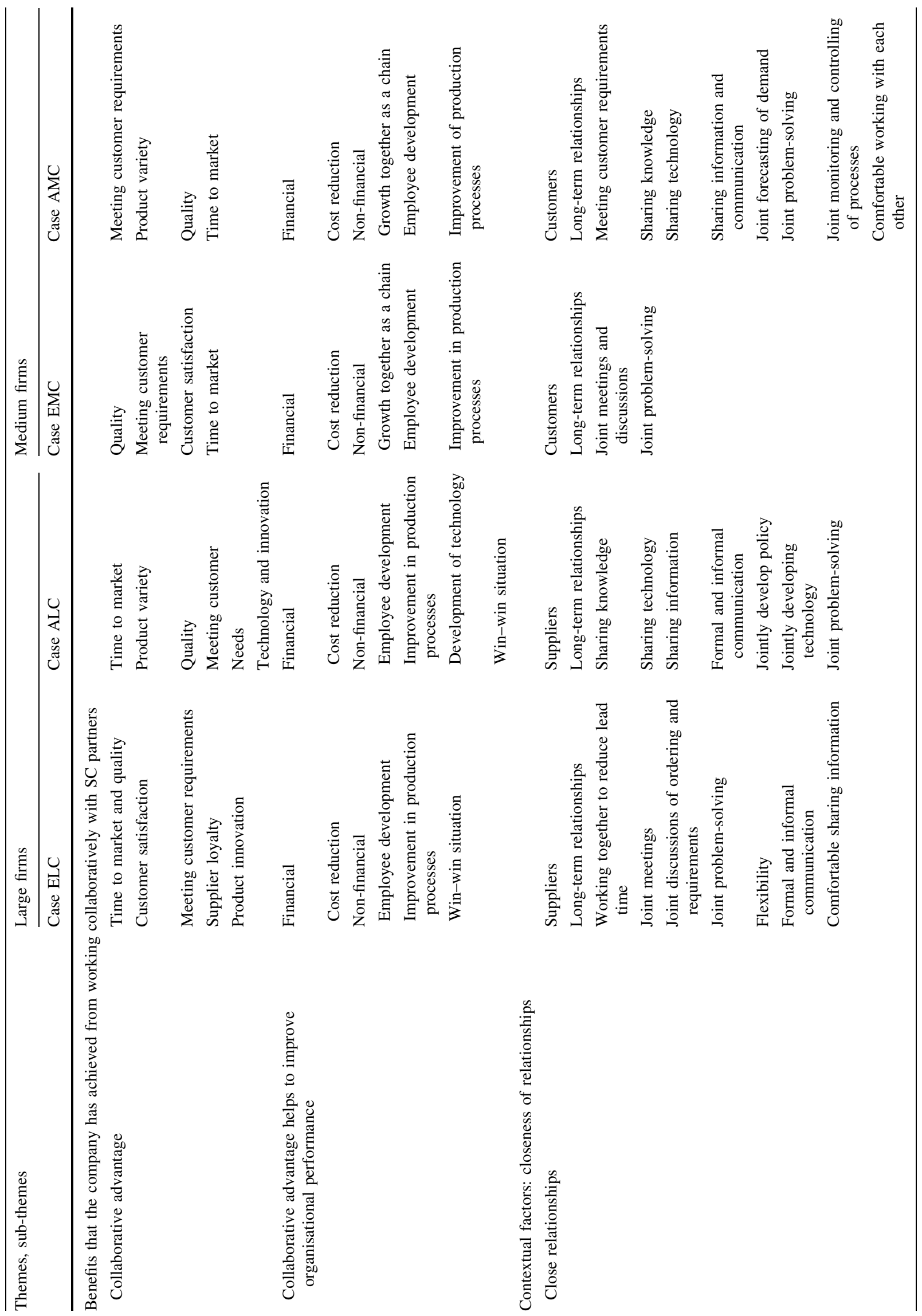




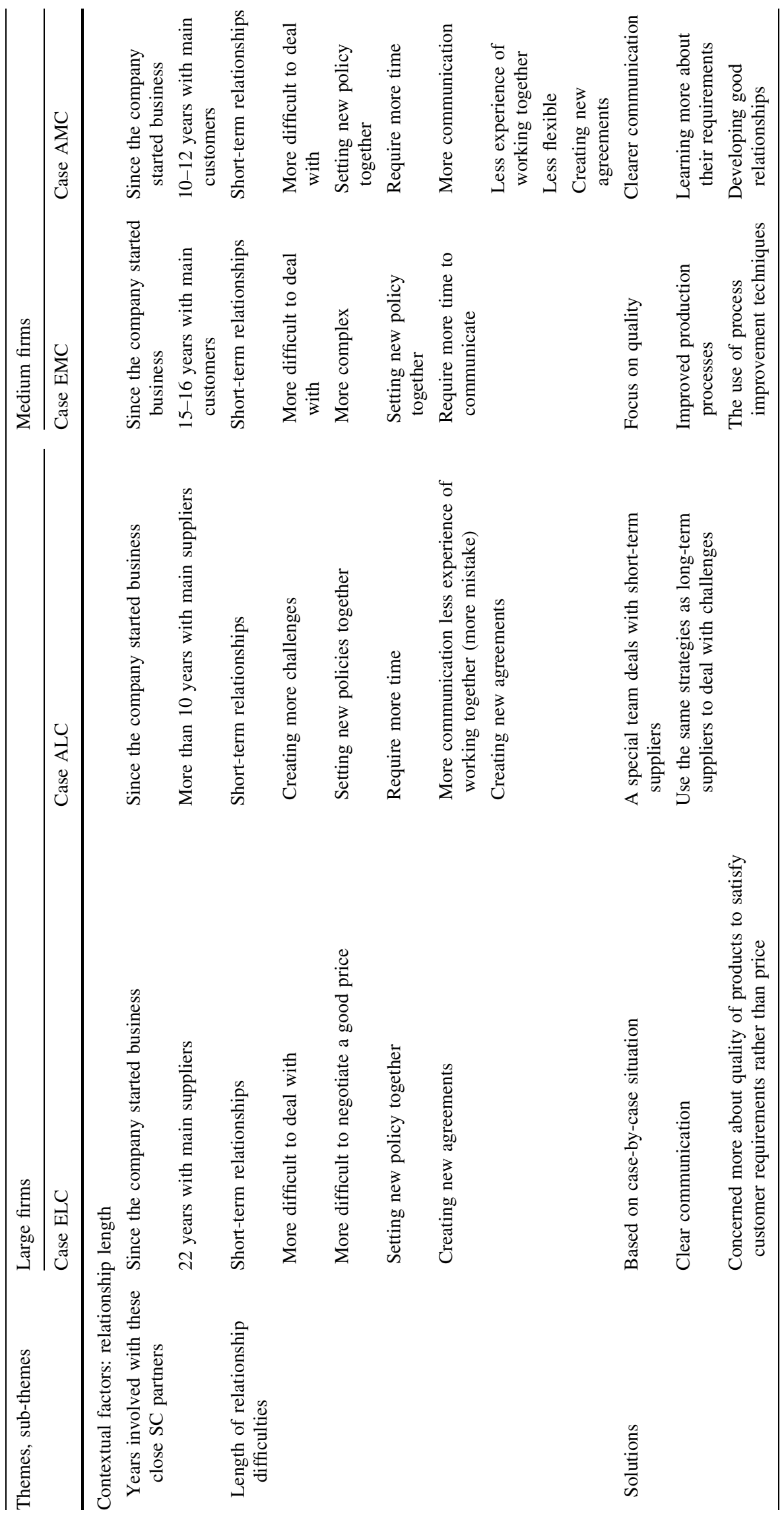




\section{References}

1. Braziotis C, Bourlakis M, Rogers H, Tannock J (2013) Supply chains and supply networks: distinctions and overlaps. Supply Chain Manag Int J 18(6):644-652. doi:10.1108/SCM-07-20120260

2. Kotzab H, Christoph T, David BG, Anders F (2014) Supply chain management resources, capabilities and execution. Prod Plann Control. doi:10.1080/09537287.2014.927932

3. Lusch RF, Vargo SL, Tanniru M (2009) Service, value networks and learning. J Acad Mark Sci 38(1):19-31. doi:10.1007/s11747008-0131-z

4. Kampstra RP, Ashayeri J, Gattorna JL (2006) Realities of supply chain collaboration. Int J Logist Manag 17(3):312-330. doi:10. 1108/09574090610717509

5. Cao M, Zhang Q (2011) Supply chain collaboration: impact on collaborative advantage and firm performance. J Oper Manag 29(3):163-180. doi:10.1016/j.jom.2010.12.008

6. Hsu C-C, Tan KC, Kannan VR, Keong Leong G (2009) Supply chain management practices as a mediator of the relationship between operations capability and firm performance. Int $\mathrm{J}$ Prod Res 47(3):835-855. doi:10.1080/00207540701452142

7. Rosenzweig ED (2009) A contingent view of e-collaboration and performance in manufacturing. J Oper Manag 27(6):462-478. doi:10.1016/j.jom.2009.03.001

8. Simchi-Levi D, Kaminsky P, Simchi-levi E (2008) Designing and managing the supply chain: concepts, strategies, and case studies. McGraw-Hill, Boston

9. Flynn BB, Huo B, Zhao X (2010) The impact of supply chain integration on performance: a contingency and configuration approach. J Oper Manag 28(1):58-71. doi:10.1016/j.jom.2009. 06.001

10. Cagliano R, Caniato F, Spina G (2006) The linkage between supply chain integration and manufacturing improvement programmes. Int J Oper Prod Manag 26(3):282-299. doi:10.1108/ 01443570610646201

11. Zacharia ZG, Nix NW, Lusch RF, Emerson RW (2009) An analysis of supply chain collaborations and their effect on performance outcomes. J Bus Logist 30(2):101-124. doi:10.1002/j. 2158-1592.2009.tb00114

12. Nyaga GN, Whipple JM, Lynch DF (2010) Examining supply chain relationships: do buyer and supplier perspectives on collaborative relationships differ? J Oper Manag 28(2):101-114. doi:10.1016/j.jom.2009.07.005

13. Min S, Roath AS, Daugherty PJ, Genchev SE, Chen H, Arndt AD, Richey RG (2005) Supply chain collaboration: what's happening? Int J Logist Manag 16(2):237-256. doi:10.1108/ 09574090510634539

14. Simatupang TM, Sridharan R (2008) Design for supply chain collaboration. Bus Process Manag J 14(3):401-418. doi:10.1108/ 14637150810876698

15. Pradabwong J, Braziotis C, Tannock J (2013) Exploring the interrelationship between business process management, supply chain collaboration, collaborative advantage and organizational performance. In: Proceedings of the 20th EurOMA Conference, Dublin, June

16. Chang JF (2006) Business process management systems. Taylor and Francis Group, New York

17. Van der Aalst, WMP, ter Hofstede, AHM, Waske, M (2003) Business process management: a survey. In: Proceedings of the international conference on business process management, BPM 2003, Eindhoven, The Netherlands, 26-27 June

18. Lindsay A, Downs D, Lunn K (2003) Business processes-attempts to find a definition. Inf Softw Technol 45(15):1015-1019. doi:10.1016/S0950-5849(03)00129-0
19. Smart PA, Maddern H, Maull RS (2009) Understanding business process management: implications for theory and practice. Br J Manag 20(4):491-507. doi:10.1111/j.1467-8551.2008.00594

20. Chen IJ, Paulraj A (2004) Towards a theory of supply chain management: the constructs and measurements. J Oper Manag 22(2):119-150. doi:10.1016/j.jom.2003.12.007

21. Qrunfleh S, Tarafdar M (2012) Supply chain information systems strategy: impacts on supply chain performance and firm performance. Int J Prod Econ 147:340-350. doi:10.1016/j.ijpe.2012.09. 018

22. Cousins C, Lamming R, Lawson B, Squire B (2008) Strategic supply management: principles, theories and practice. Pearson Education Limited, Essex

23. Hung RY-Y (2006) Business process management as competitive advantage: a review and empirical study. Total Qual Manag Bus Excell 17(1):21-40. doi:10.1080/14783360500249836

24. Maddern H, Maull R, Smart A, Baker P (2007) Customer satisfaction and service quality in UK financial services. Int J Oper Prod Manag 27(9):999-1019. doi:10.1108/01443570710775838

25. McCormack K, Ladeira MB, De Oliveira MPV (2008) Supply chain maturity and performance in Brazil. Supply Chain Manag Int J 13(4):272-282. doi:10.1108/13598540810882161

26. Škrinjar R, Bosilj-Vukšic V, Indihar-Štemberger M (2008) The impact of business process orientation on financial and non-financial performance. Bus Process Manag J 14(5):738-754. doi:10.1108/14637150810903084

27. Ramanathan U, Gunasekaran A (2014) Supply chain collaboration: impact of success in long-term partnerships. Int J Prod Econ 147:252-259. doi:10.1016/j.ijpe.2012.06.002

28. Wiengarten F, Humphreys P, Cao G, Fynes B, McKittrick A (2010) Collaborative supply chain practices and performance: exploring the key role of information quality. Supply Chain Manag Int J 15(6):463-473. doi:10.1108/13598541011080446

29. Barratt M (2004) Understanding the meaning of collaboration in the supply chain. Supply Chain Manag Int J 9(1):30-42. doi:10. 1108/13598540410517566

30. Malhotra A, Gosain S, El Sawy OA (2005) Absorptive capacity configurations in supply chains: gearing for partner-enabled market knowledge creation. MIS Q 29(1):145-187

31. Fawcett SE, Magnan GM, McCarter MW (2008) A three-stage implementation model for supply chain collaboration. J Bus Logist 29(1):93-112. doi:10.1002/j.2158-1592.2008.tb00070.x

32. Li S, Ragu-Nathan B, Ragu-Nathan TS, Subba Rao S (2006) The impact of supply chain management practices on competitive advantage and organizational performance. Omega 34(2):107124. doi:10.1016/j.omega.2004.08.002

33. Vereecke A, Muylle S (2006) Performance improvement through supply chain collaboration in Europe. Int J Oper Prod Manag 26(11):1176-1198. doi:10.1108/01443570610705818

34. Kotzab H, Teller C, Grant Db, Sparks L (2011) Antecedents for the adoption and execution of supply chain management. Supply Chain Manag Int J 16(4):231-245. doi:10.1108/13598541111139053

35. Sila I (2007) Examining the effects of contextual factors on TQM and performance through the lens of organizational theories: an empirical study. J Oper Manag 25(1):83-109. doi:10.1016/j.jom. 2006.02.003

36. Tang X, Rai A (2012) The moderating effects of supplier portfolio characteristics on the competitive performance impacts of supplier-facing process capabilities. J Oper Manag 30(1-2):85-98. doi:10.1016/j.jom.2011.07.001

37. Hou C-K (2012) Examining the effect of user satisfaction on system usage and individual performance with business intelligence systems: an empirical study of Taiwan's electronics industry. Int $\mathrm{J}$ Inf Manage 32(6):560-573. doi:10.1016/j.ijin fomgt.2012.03.001 
38. Lavastre O, Gunasekaran A, Spalanzani A (2014) Effect of firm characteristics, supplier relationships and techniques used on supply chain risk management (SCRM): an empirical investigation on French industrial firms. Int J Prod Res 52(11):3381-3403. doi:10.1080/00207543.2013.878057

39. Paiva EL, Roth AV, Fensterseifer JE (2008) Organizational knowledge and the manufacturing strategy process: a resourcebased view analysis. J Oper Manag 26(1):115-132. doi:10.1016/j. jom.2007.05.003

40. Slone RE, Mentzer JT, Dittmann JP (2007) Are you the weakest link in your company's supply chain? Harv Bus Rev 85(9):116-127

41. Davis EW, Spekman RS (2004) Extended enterprise: gaining competitive advantage through collaboration supply chains. Prentice Hall Financial Times, New Jersey

42. Fawcett SE, Osterhaus P, Magnan GM, Brau JC, McCarter MW (2007) Information sharing and supply chain performance: the role of connectivity and willingness. Supply Chain Manag Int J 12(5):358-368. doi:10.1108/13598540710776935

43. Holweg M, Disney S, Holmstrom J, Smaros J (2005) Supply chain collaboration: making sense of the strategy continuum. Eur Manag J 23(2):170-181. doi:10.1016/j.emj.205.02.008

44. Zacharia ZG, Nix NW, Lusch RF (2011) Capabilities that enhance outcomes of an episodic supply chain collaboration. J Oper Manag 29(6):591-603. doi:10.1016/j.jom.2011.02.001
45. Dyer JH (2000) Collaborative advantage: Winning through extended enterprise supplier networks. Oxford University Press, New York

46. Eisenhardt KM, Martin JA (2000) Dynamic capabilities: what are they? Strateg Manag J 21(10-11):1105-1121. doi:10.1002/10970266(200010/11)21:10/11

47. Hendricks KB, Singhal VR, Stratman JK (2007) The impact of enterprise systems on corporate performance: a study of ERP, SCM, and CRM system implementations. J Oper Manag 25(1):65-82. doi:10.1016/j.jom.2006.02.002

48. Chen IJ, Paulraj A, Lado AA (2004) Strategic purchasing, Supply chain management and firm performance. J Oper Manag 22(5):505-523. doi:10.1016/j.jom.2004.06.002

49. Yin RK (2014) Case study research: design and methods, 5th edn. Sage publications Inc, London

50. Creswell JW, Clark VLP (2011) Designing and conducting mixed methods research. SAGE Publication Inc, London

51. Braun V, Clarke V (2013) Successful qualitative research: a practical guide for beginners. Sage Publications, London

52. Creswell JW (2007) Qualitative inquiry research design: Choosing among five approaches, 2nd edn. SAGE Publication Ltd, London

53. Miles MB, Huberman AM, Saldaña J (2014) Qualitative data analysis: a methods sourcebook, 3rd edn. Sage Publications, London 